\title{
Cryogenic Pressure Control Modeling for Ellipsoidal Space Tanks
}

\author{
Alfredo Lopez ${ }^{1}$, Gary D. Grayson ${ }^{2}$, and Frank O. Chandler ${ }^{3}$ \\ The Boeing Company, Huntington Beach, CA, 92647 \\ Leon J. Hastings ${ }^{4}$ \\ Alpha Technology, Inc., Huntsville, Alabama, 35812 \\ and \\ Ali Heyadat ${ }^{5}$ \\ NASA Marshall Space Flight Center, Huntsville, Alabama, 35812
}

\begin{abstract}
A computational fluid dynamics (CFD) model is developed to simulate pressure control of an ellipsoidal-shaped liquid hydrogen tank under external heating in normal gravity. Pressure control is provided by an axial jet thermodynamic vent system (TVS) centered within the vessel that injects cooler liquid into the tank, mixing the contents and reducing tank pressure. The two-phase cryogenic tank model considers liquid hydrogen in its own vapor with liquid density varying with temperature only and a fully compressible ullage. The axisymmetric model is developed using a custom version of the commercially available FLOW-3D software. Quantitative model validation is provided by engineering checkout tests performed at Marshall Space Flight Center in 1999 in support of the Solar Thermal Upper Stage Technology Demonstrator (STUSTD) program. The engineering checkout tests provide cryogenic tank self-pressurization test data at various heat leaks and tank fill levels. The predicted self-pressurization rates, ullage and liquid temperatures at discrete locations within the STUSTD tank are in good agreement with test data. The work presented here advances current CFD modeling capabilities for cryogenic pressure control and helps develop a low cost CFD-based design process for space hardware.
\end{abstract}

\section{Nomenclature}

$d p / d t=$ ullage pressure rise rate

$V_{\max }=$ maximum velocity within the domain

\section{Introduction}

$\mathrm{H}^{\mathrm{s}+\mathrm{at}}$ IGH energy cryogenic propellants are being considered for NASA's space exploration program including the stages for Earth departure, Lunar descent, and Lunar ascent. Cryogenic fluid management (CFM) technology and advanced development are essential to the development of these upper stages. NASA and it's industrial partners are committed to an advanced development/technology program that will broaden the experience base for the entire CFM community. The high cost of, and limited opportunities for, microgravity experiments have motivated the Marshall Space Flight Center (MSFC)/Boeing team to aggressively explore combinations of ground testing and analytical modeling to the greatest extent possible.

\footnotetext{
${ }^{1}$ Associate Engineer/Scientist, Propulsion \& Cryogenic Technologies, 5301 Bolsa, Ave/H012-2B200, Member.

${ }^{2}$ Associate Technical Fellow, Propulsion \& Cryogenic Technologies, 5301 Bolsa Ave/H012-2B201, Senior Member.

${ }^{3}$ Director, Propulsion \& Cryogenic Technologies, 5301 Bolsa Ave/H012-2B201, Associate Fellow.

${ }^{4}$ CFM Technology Consultant, Propulsion Systems Dept. ER23/ATI, Associate Member.

${ }^{5}$ Aerospace Engineer, Cryogenic Fluid Management Technology Team, Propulsion Systems Dept. ER23, Senior Member.
} 
Cryogenic propellant CFD tools provide low cost design solutions to the aerospace industry. During the Space Shuttle program design activity related to propellant fluid management was performed based on solid engineering principles and techniques but generally with hand analysis, slide rules, automatic calculators and with the application of computational tools and codes assisted by batch computer processing. Large computer programs would take overnight for answers to be available for design application. Now engineering tools for analysis and design are available for use on desktops and workstations with near immediate answers to posed design problems. This rapidity in the development of key design information has accelerated the design activity to the point where preliminary designs can be accomplished in a very short period of time compared to the Space Shuttle era. The increased fidelity of the design information has lowered the cost and schedule risks associated with extremely complex and one of a kind engineering feats. However the process of proving that the design is adequate for all environments has still relied heavily on the performance of ground testing supplemented where possible with orbital testing. With the advent of modern computational design tools applying CFD to internal flow dynamic systems, the requirement to test every aspect of the applicable environment is no longer required. As with the CFD tools used to assess the aerodynamics of supersonic to hypersonic flight with anchor runs using the wind tunnel, so it can now be with the new CFD tools for analysis of fluid flow interior to cryogenic propellant tankage with appropriate anchoring using ground testing. The ability to validate a generic CFD model to various tank geometries and internal cryogenic fluid management devices demonstrates the flexibility and universality of this CFD modeling technique. This new capability allows increased fidelity in the understanding of the fluid motion of the propellants during normal and low gravity conditions as they apply to low gravity cryogenic fluid management issues providing a low cost CFD-based design process for space hardware.

Reduced gravity propellant tank pressure control is an enabling technology for implementing in-space cryogenic propulsion. The state of the art for upper stage tank pressure control is to settle the propellant and vent as required. However, auxiliary systems for propellant settling incur weight penalties in the form of setting propellant and hardware. In addition, venting/resettling can become necessary at inopportune times in a mission timeline, thereby complicating mission operations. The thermodynamic vent system (TVS) concept enables tank pressure control and venting without resettling. Two ground test series, one for Boeing and one for SRS Technologies, with liquid hydrogen (LH2) have been conducted at MSFC using the $2 \mathrm{~m}^{3}\left(71 \mathrm{ft}^{3}\right)$ Solar Upper Stage Technology Demonstrator (STUSTD) tank (Fig. 1) to demonstrate reduced gravity pressure control. Details of the STUSTD program and engineering tests are presented in Ref. 2 . This paper focuses on the analytical correlation of the normal gravity pressure rise rate and active TVS performance data using updated versions of FLOW-3D computational fluid dynamics (CFD) software from Flow Science, Inc.

The overall strategy is to first anchor the CFD models with normal gravity data, then extrapolate the models to reduced gravity conditions and evaluate the effects of acceleration environment on pressure control thermodynamics. It is believed that the CFD modeling can be used to significantly decrease reliance on costly and infrequent CFM orbital flight experiments. Subsequent sections discuss the use of FLOW-3D CFD modeling to correlate the STUSTD tank pressure rise rate test data.

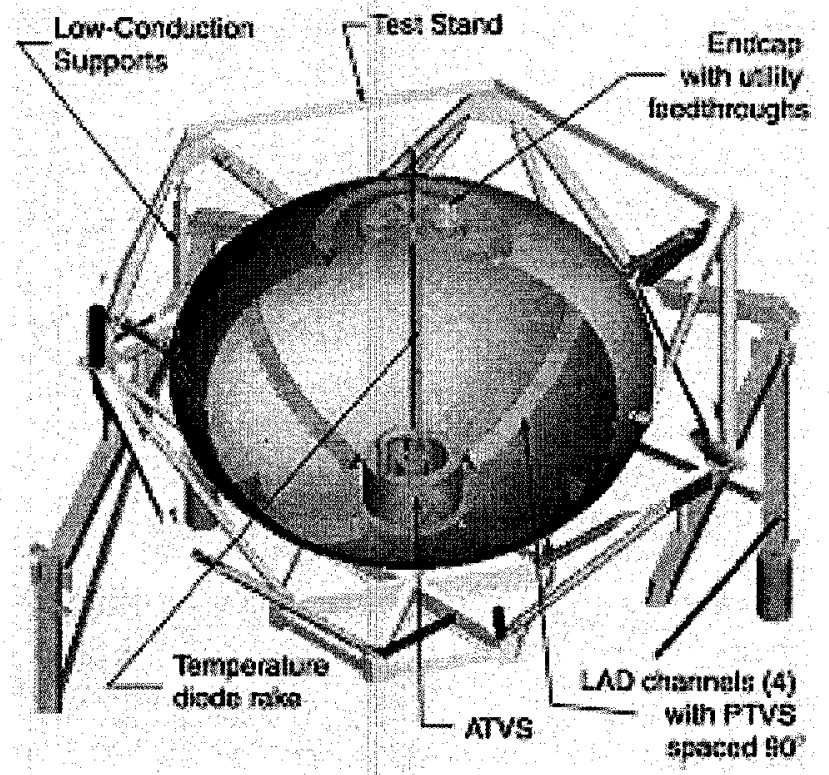

Figure 1. STUSTD Tank Configuration. 


\section{Approach}

\section{A. FLOW-3D Software}

FLOW-3D is a general Navier-Stokes equation solver with an extensive history of cryogenic tank modeling. FLOW-3D allows several options to be enabled based on what is important to the problem. The present two-phase cryogenic tank model is developed using a custom version of the commercially available FLOW-3D software. The customization enables the model to treat phase change effects at the liquid-gas interface. First order approximations for momentum and energy equations including the two equation $k-\varepsilon$ and Renormalization-Group (RNG) turbulence model are enabled. The ullage region is fully compressible and liquid density varies with temperature only. Modeling the heat transfer between liquid, gas and tank walls is included to capture thermal stratification within the fluids. For details of the formulations and assumptions within the FLOW-3D code see Ref. 5.

\section{B. Model Description}

The model uses a 3,366 cell axisymmetric mesh to simulate the $71 \mathrm{ft}^{3}$ ellipsoidal STUSTD tank (Fig. 2). The mesh is derived from the S-IVB mesh (Ref. 1) previously shown to be independent of grid size therefore the current STUSTD mesh is expected to provide a grid insensitive solution. The tank has a width of 5.78 -ft. and a height of 4.08 -ft. Liquid acquisition devices are omitted from the model because the engineering checkout tests do not include LAD operation. The ATVS is located in the center of the tank and is $1-\mathrm{ft}$. in diameter and $0.63-\mathrm{ft}$. tall. The outlet of the vertical jet is 0.14 -ft. (1.7-in.) in diameter.

A series of tank wall heaters capable of delivering $20 \mathrm{~W}$ to $40 \mathrm{~W}$ of heating are imbedded in the tank insulation. Due to the axisymmetric mesh, the STUSTD

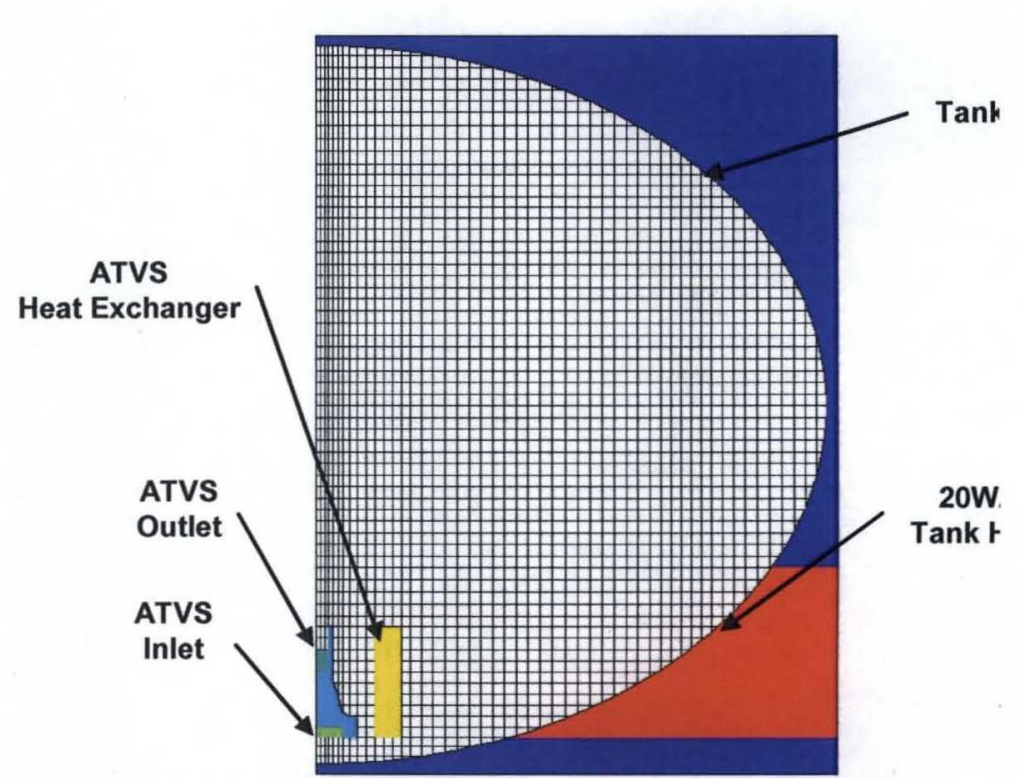

Figure 2. STUSTD Model Mesh and Tank Geometry. model incorporates these variable power tank heaters as solid obstacles adjacent to the bulk liquid. The actual tank heaters are approximately 6 inches wide by 26 inches long. Four of these tank heater strips are evenly distributed on the tank wall.

The active TVS body is considered adiabatic thus contributing a negligible amount of heat to the liquid. The selfpressurization models are initially quiescent. The liquid is assumed saturated at a given tank pressure and allowed to heat up. Ullage stratification profiles are derived from available test data and applied on a case by case basis.

Table 1 lists the test cases considered in the present analysis. The focus is on tank self-pressurization and ATVS performance. Normal-gravity simulations are developed from previously performed physical tests conducted at NASA MSFC. Test Case 3 includes ATVS activation while all other cases strictly treat tank self-pressurization under external heating. The tank heat leak is distributed between the tank wall and the imbedded heater obstacles. When heaters are not used the incoming tank heat leak is evenly distributed along the tank walls including the surface of the inactive heaters.

\begin{tabular}{|c|c|c|c|c|}
\hline Test Case & Test Fluid & Heat Leak Rate & Fill Level & $\begin{array}{c}\text { Mixer Type \& Flow } \\
\text { Rate }\end{array}$ \\
\hline 1 & LH2 & $25.7 \mathrm{~W}$ & $87 \%$ & none \\
\hline 2 & LH2 & $25.7 \mathrm{~W}$ & $44 \%$ & none \\
\hline 3 & LH2 & $6.7 \mathrm{~W}$ & $90 \%$ & axial jet $/ 27 \mathrm{gpm}$ \\
\hline
\end{tabular}

Table 1. STUSTD Normal Gravity Test Cases. 


\section{Results and Discussion}

Detailed model results for normal gravity test cases are presented in Figures 3 through 14. Ullage pressure histories, ullage temperature histories, liquid temperature histories, temperature contour, and velocity field plots for each case are displayed. Ullage pressure and temperatures are measured at 44-in. from the bottom of the tank while liquid temperatures are recorded in the bulk liquid. Due to the different fill levels, some test cases record liquid temperatures at 25 -in. or 15 -in. from the bottom of the tank. The specific temperature sensor location is indicated on each plot.

\section{A. Self-Pressurization}

In general, the normal gravity results closely follow the trends evident in the test data. Several results from selected cases are interpreted and discussed in detail below.

In Case $1(25.7 \mathrm{~W}, 87 \%$ fill $)$ shown in Figs. 3 to 6 the tank heaters operate at half capacity $(20 \mathrm{~W})$ and $5.7 \mathrm{~W}$ and remain evenly distributed along the tank walls. Uniform saturated conditions at 34 psia (42.3 R) and a quiescent velocity field are assumed for the initial conditions. The large natural convection vortices generated in the bulk liquid by the tank heaters are disperse and slow on the order of $0.03 \mathrm{ft} / \mathrm{s}$. This shows that the tank heaters have a impact on the velocity field within the bulk liquid and influence the magnitude of this motion by how much energy they introduce. Thermal stratification of the ullage is high but relatively constant (approximately $9 \mathrm{R}$ ) throughout the self-pressurization phase with a peak temperature of $53.7 \mathrm{R}$. Model results predict an average ullage pressurization rate of $1.0 \mathrm{psi} / \mathrm{hr}$ which agrees well the measured $0.92 \mathrm{psi} / \mathrm{hr}$ rate. Predicted ullage and liquid temperatures at 44 inches and 25 inches respectively also agree well with measured test data and are within $0.5 \mathrm{R}$ of actual sensors readings.

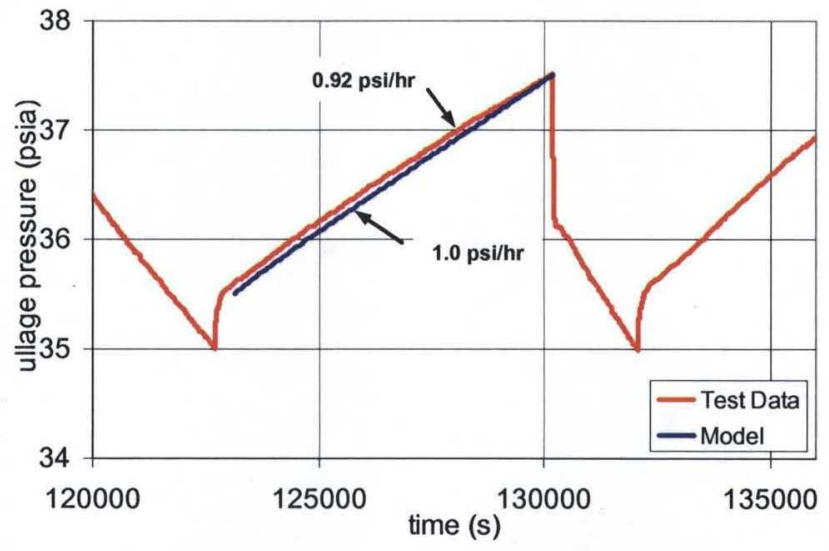

Figure 3. Case 1 Ullage Pressure History.

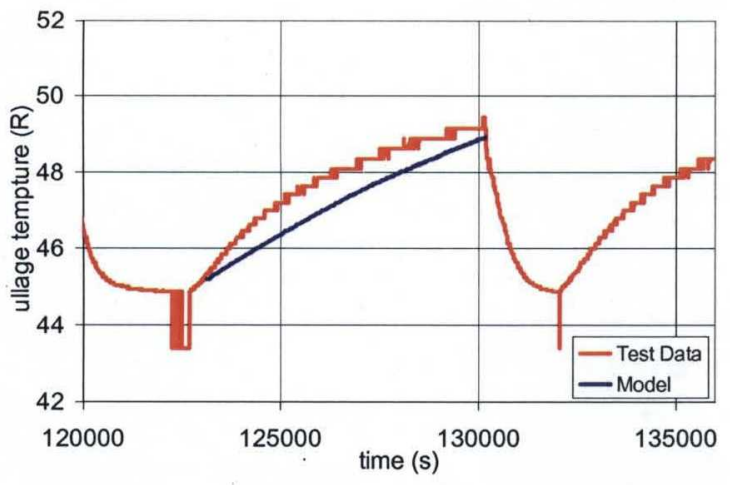

Figure 4. Case 1 Ullage Temperature History.

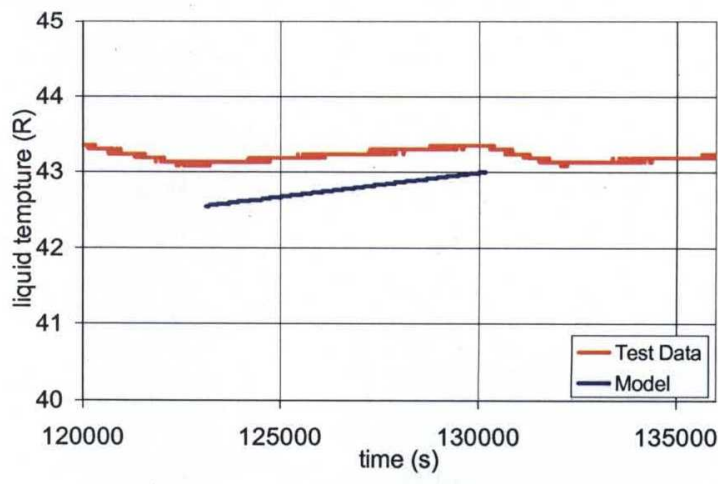

Figure 5. Case 1 Liquid Temperature History (25-in.). 


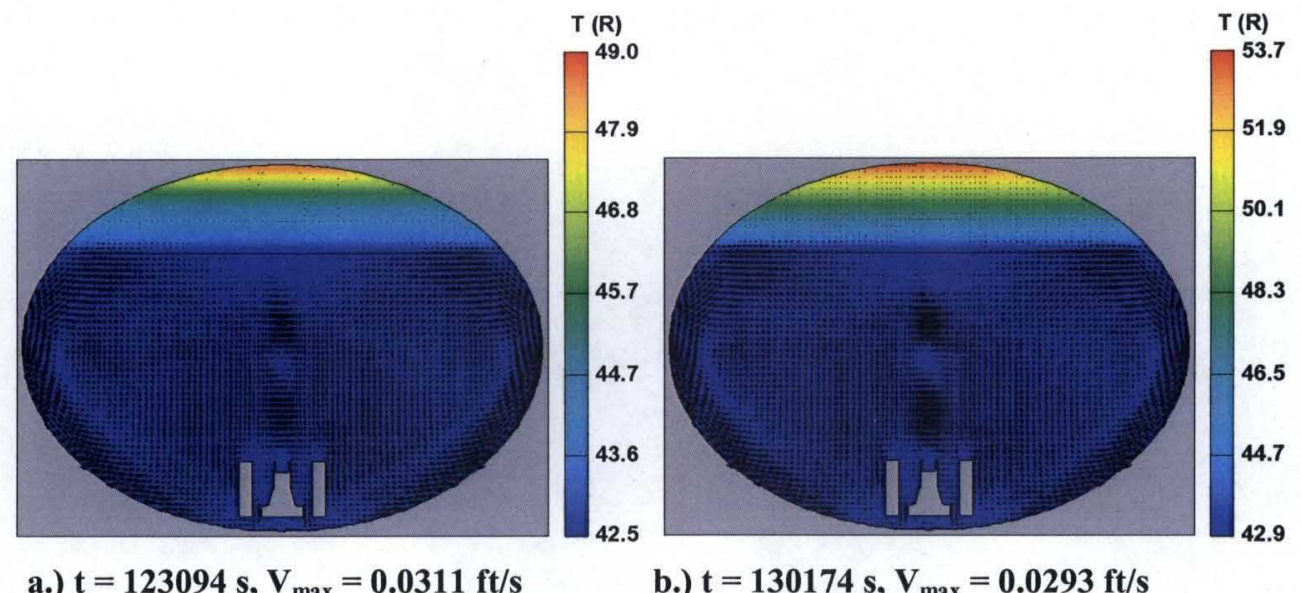

Figure 6. Case 1 Temperature and Velocity Field Plots.

For Case 2 (25.7 W, 44\% fill) shown in Figs. 7 to 10, the tank heaters are operating at $20 \mathrm{~W}$. The remaining 5.7 $\mathrm{W}$ are evenly distributed along the tank walls. The tank is initially quiescent and assumed saturated at 35 psia (42.5 $\mathrm{R})$. The ullage is stratified by $8.5 \mathrm{R}$ to simulate the temperature distribution in the ullage during the actual test. Both model and test data illustrate a $1.45 \mathrm{psi} / \mathrm{hr}$ tank pressurization rate. Ullage temperature results illustrate a $2.5 \mathrm{R}$ rise over the 2 psi pressure band. Predicted liquid temperature results at 15 inches from the bottom of the tank agree with test data and show a small rise in temperature. The temperature and velocity field plots illustrate similar bulk liquid fluid dynamics for Case 2 as for Case 1. Ullage thermal stratification is slightly higher at the lower fill level.

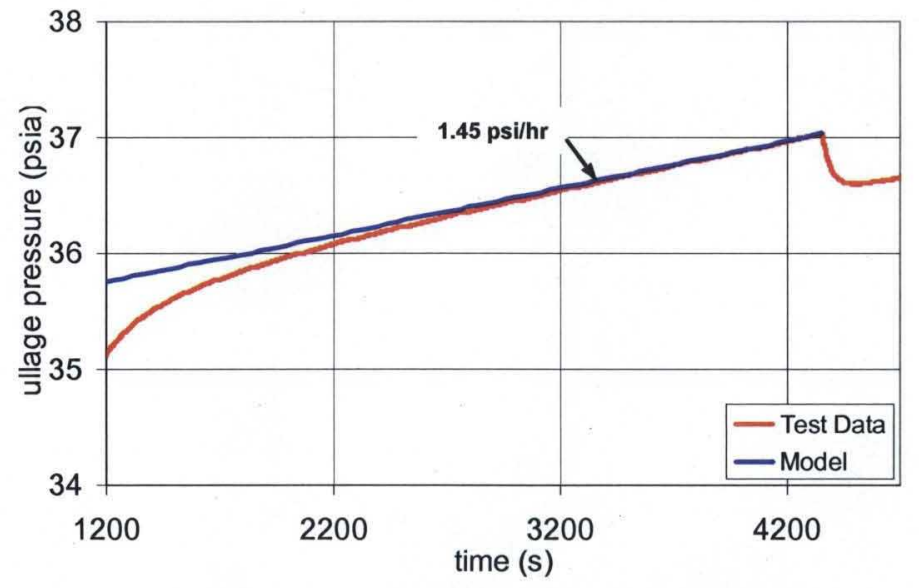

Figure 7. Case 2 Ullage Pressure History.

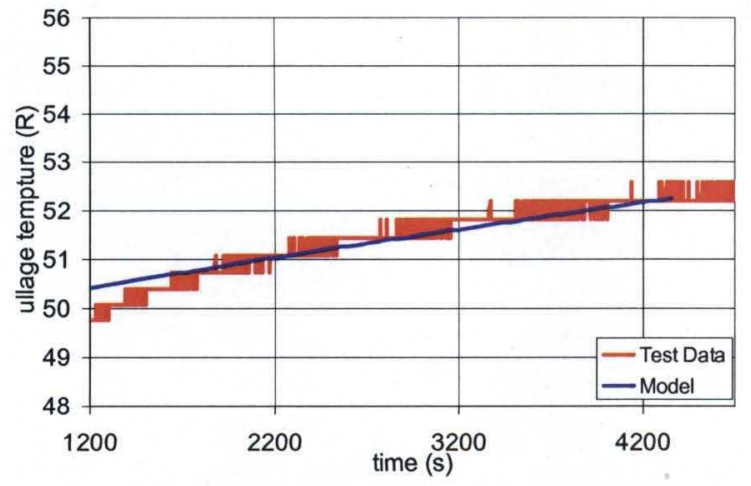

Figure 8. Case 2 Ullage Temperature History.

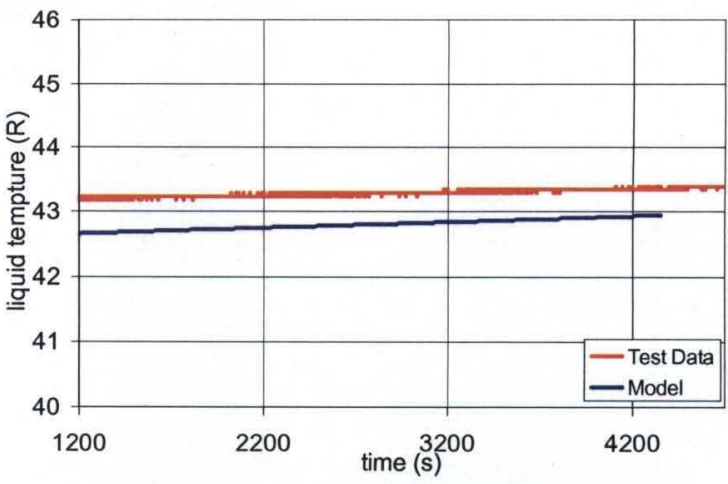

Figure 9. Case 2 Liquid Temperature History (15-in.). 


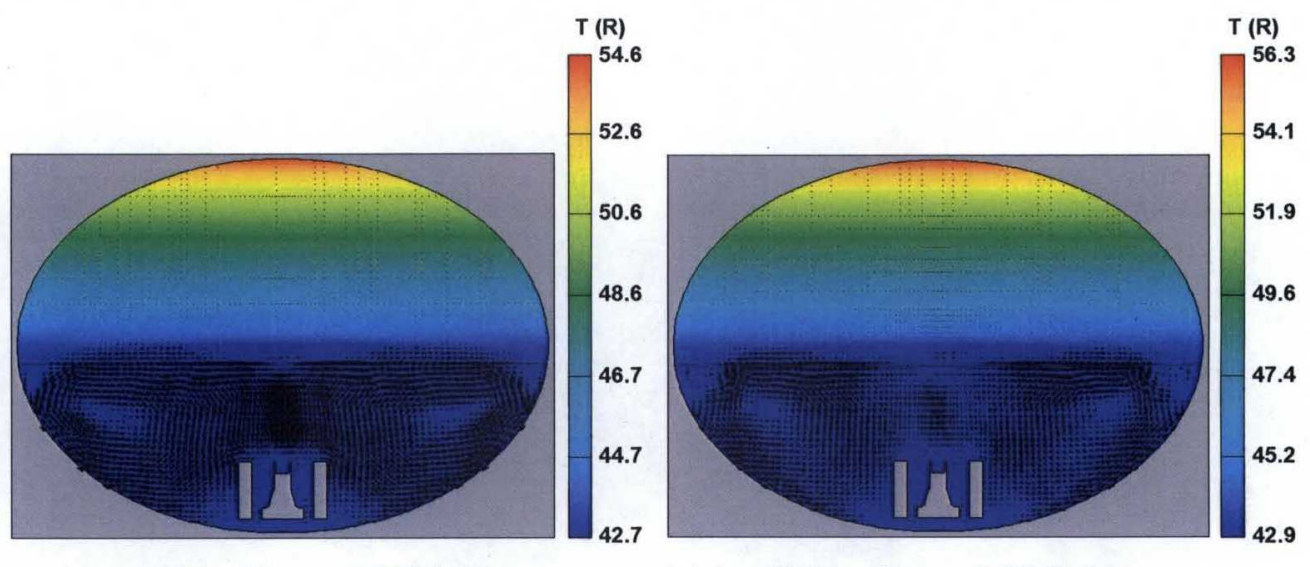

a.) $t=1837 \mathrm{~s}, V_{\max }=0.0934 \mathrm{ft} / \mathrm{s}$

b.) $\mathrm{t}=4277 \mathrm{~s}, \mathrm{~V}_{\max }=0.0840 \mathrm{ft} / \mathrm{s}$

Figure 12. Case 2 Temperature and Velocity Field Plots.

\section{B. ATVS Activation}

For test Case 3 where the active TVS is used, temperature and velocity field plots for the self-pressurization, active TVS, and repressurization phases of the pressure control cycle are illustrated (Fig. 14). The first figure (denoted by "a") illustrates the temperature and velocity distribution once the tank has reached it upper pressure limit, hence the end of the self-pressurization phase. The second figure (denoted by "b") displays the temperature and velocity field at the end of the TVS phase where the active TVS has destratified the ullage and dropped the tank pressure to its lower limit. The third figure (denoted by "c") illustrates the tank conditions at the end of the repressurization phase where the

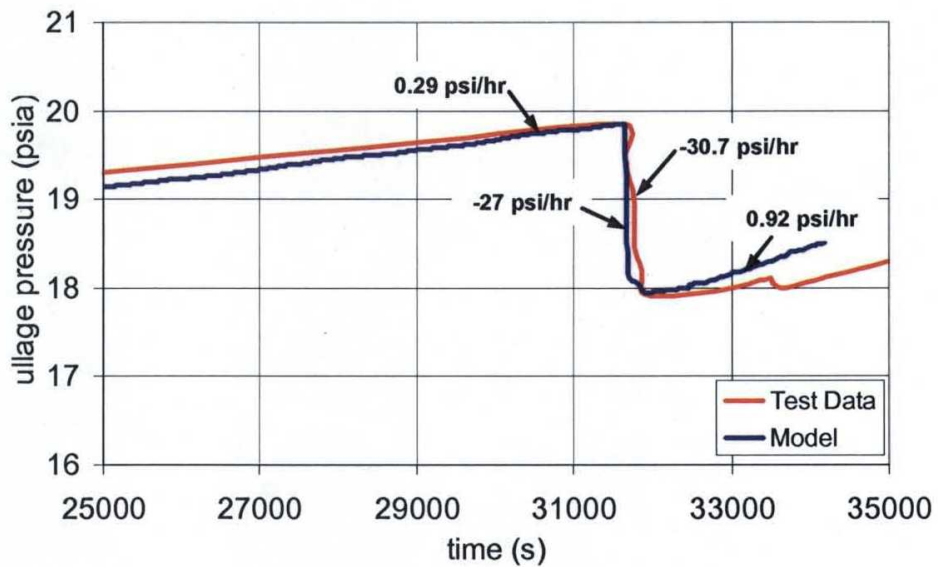

Figure 11. Case 3 Ullage Pressure History. tank has reached its upper pressure limit once again.

Case 3 (6.7 W, 90\% fill, $27 \mathrm{gpm}$ ) is summarized graphically in Figs. 11 to 14 and simulates the engineering checkout test performed following boil-off characterization of the STUSTD tank. This steady boil-off test determined a total system heat leak of $6.7 \mathrm{~W}$. With heaters off and $6.7 \mathrm{~W}$ evenly distributed along the tank walls, the STUSTD tank is locked up and allowed to pressurize to approximately 20 psia at which point LH2 at $36.8 \mathrm{R}$ is jetted axially at a rate of $27 \mathrm{gpm}$ into the bulk liquid to mix the tank contents and control tank pressure. In Case 3 the RNG turbulence model is used instead of the original $k-\varepsilon$ model from previous work (Ref. 1). RNG is more stable and provides better results for axial jet mixer and it is recommended by the FLOW-3D developers for axial jet problems. Once the tank pressure drops to approximately 18 psia the active TVS is shut down and the tank re-pressurizes. During tank repressurization the tank heaters are powered up to $40 \mathrm{~W}$. The model assumes uniform saturated LH2 conditions at $16.5 \mathrm{psia}(37.2 \mathrm{R})$. The tank is assumed to be quiescent. Predicted ullage pressure rise rates agree very well with available test data. During self-pressurization, the STUSTD tank reaches $20 \mathrm{psia}$ at a rate of $0.29 \mathrm{psi} / \mathrm{hr}$. The tank remains relatively quiescent with maximum velocities on the order of $0.04 \mathrm{ft} / \mathrm{s}$. Natural convection boundary layers are noticed as warm liquid is transported toward the free surface by buoyant forces. As expected, the ullage becomes thermally stratified. At the end of self-pressurization ( 20 psia) peak temperatures reach $58.1 \mathrm{R}$ and the ullage is thermally stratified by approximately $20 \mathrm{R}$.

Test data for Case 3 is reported in Ref. 2. Ullage temperature data at 44 inches and 41 inches and liquid temperature data at 30 inches and 15 inches from the bottom of the tank are available but for only approximately 


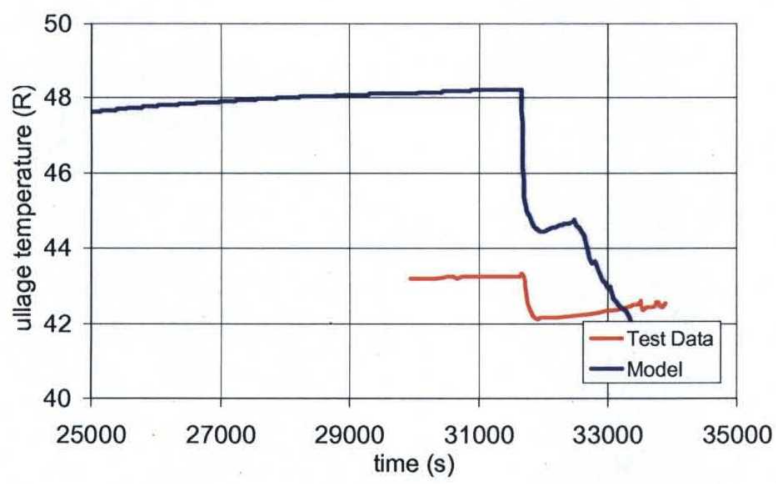

Figure 12. Case 3 Ullage Temperature History.

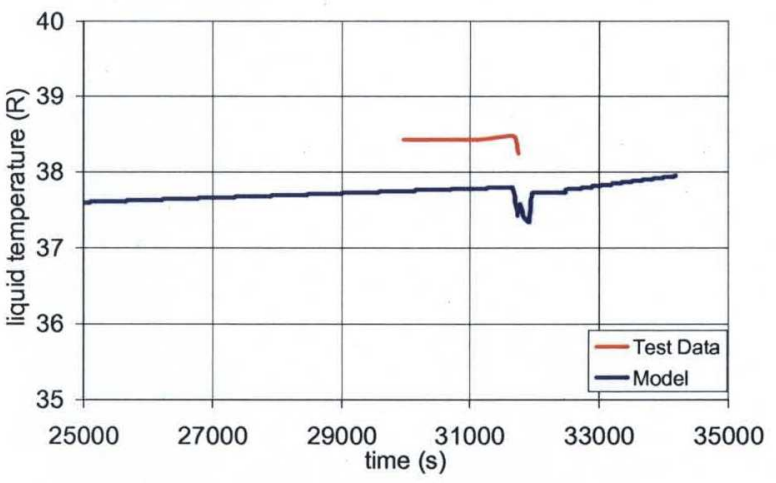

Figure 13. Case 3 Liquid Temperature History (30-in.).

1,500 seconds before and after active TVS activation. The model records ullage pressure and temperature at 44 inches and liquid temperatures at 30 inches from the bottom of the tank. Predicted ullage temperatures are higher than measured test data. This may be due to constant heat leak boundary conditions that typically over predict energy exchange between tank walls and fluids. Both model and test liquid temperatures show negligible change during tank self-pressurization.

At 31,658 seconds (Fig. 14a), the active TVS in Case 3 is turned on. Liquid hydrogen at $36.8 \mathrm{R}$ is jetted through the outlet into the bulk liquid at a rate of $27 \mathrm{gpm}$. The predicted average ullage pressure drop (-27 psi/hr) during

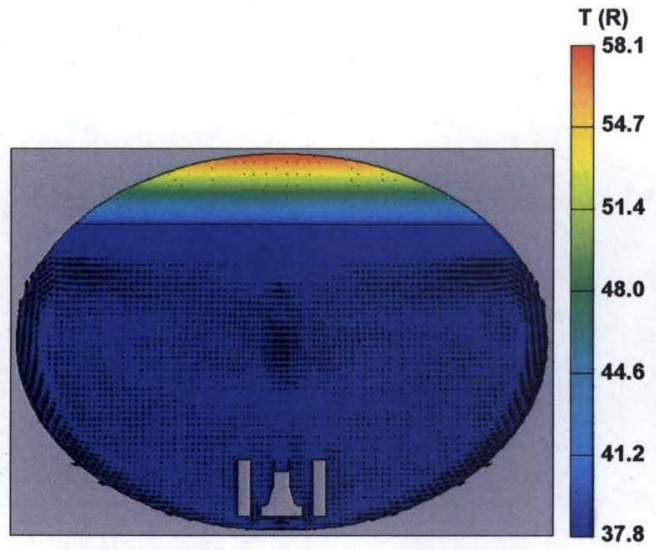

a.) $t=31658 \mathrm{~s}, \mathrm{~V}_{\max }=0.0413 \mathrm{ft} / \mathrm{s}$

b.) $t=31908 \mathrm{~s}, \mathrm{~V}_{\max }=3.82 \mathrm{ft} / \mathrm{s}$

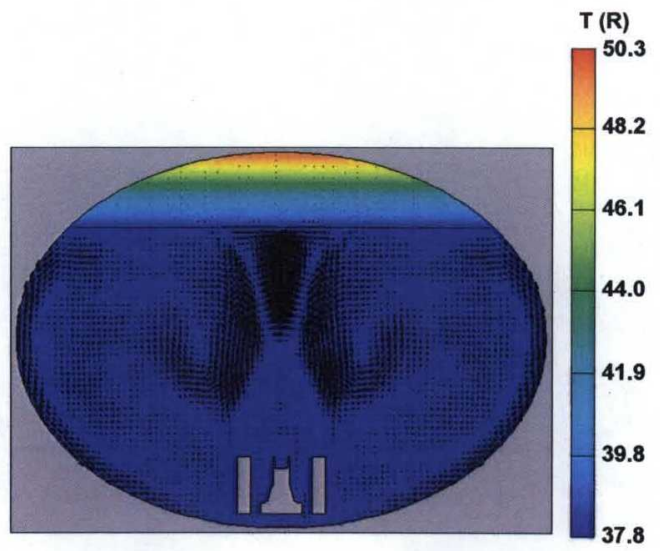

c.) $\mathbf{t}=\mathbf{3 7 8 9 8 \mathrm { s } ,} \mathrm{V}_{\max }=\mathbf{0 . 0 7 7 1} \mathrm{ft} / \mathrm{s}$

Figure 14. Case 3 Temperature and Velocity Field Plots. 
active TVS operation closely follows test data $(-30.7 \mathrm{psi} / \mathrm{hr})$. The jet penetrates the bulk liquid short of the free surface but generates enough mixing with the bulk liquid to drop ullage thermal stratification to approximately $16 \mathrm{R}$ and peak temperature to $52.9 \mathrm{R}$ at the end of the TVS phase (18 psia).

Following TVS activation the heaters are turned on and operated at $40 \mathrm{~W}$. The tank quickly begins to repressurize at a rate of $0.92 \mathrm{psi} / \mathrm{hr}$. At approximately 6,000 seconds after the TVS phase, residual motion from the jet is coupled with heater generated natural convection boundary layers and large scale vortices continue to circulate within the liquid $(0.07 \mathrm{ft} / \mathrm{s})$. This residual motion is mostly likely responsible for the decrease in ullage temperature observed in the model results.

The self-pressurization and destratification model results illustrate steady ullage pressure rise rates and temperatures that agree with test data. Important cryogenic tank thermodynamic and fluid dynamic phenomena, such as natural convection boundary layers and ullage thermal stratification are successfully captured by the model. A summary of the normal gravity self-pressurization results is given in Table 2. The table provides an overall perspective on how the average self-pressurization rate varies with different liquid fill levels and external heating conditions and illustrates that higher heat leaks result in higher tank self-pressurization rates. As more heat enters the ullage the tank pressure begins to rise at a faster rate. Additionally, for a given heat leak low fill fraction cases exhibit higher ullage pressure rise rates. For example, at $25.7 \mathrm{~W}$ the $44 \%$ fill (Case 2) case yields a selfpressurization rate of approximately $1.45 \mathrm{psi} / \mathrm{hr}$ while at an $87 \%$ fill (Case 1) the ullage pressure rise rate is 1.0 psi/hr. With more liquid in the tank the incoming heat is absorbed by the higher thermal capacity liquid this subsequently slows down tank pressurization.

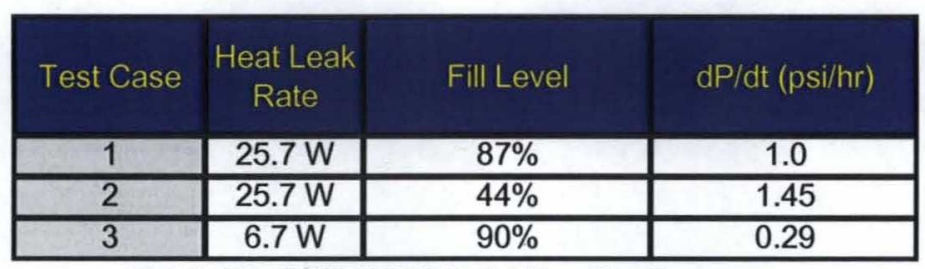

Table 2. STUSTD Model Results Summary.

\section{Conclusion}

The STUSTD cryogenic tank pressure control model has successfully demonstrated self-pressurization and thermal destratification in normal gravity for the elliptical space tank for a variety of fills and heating conditions. The predicted ullage pressurization rates agree with test data. Small ullage bubble model results predict slightly higher pressurization rates than test data. Constant power boundary conditions prescribed at the tank walls and heaters are potentially responsible for the higher pressurization rates. Ullage and liquid temperatures generally follow test data. Tank heater-liquid dynamics, natural convection boundary layers, ullage thermal stratification, and ATVS operation are successfully captured by the numerical simulations. The modeled axial jet mixes the bulk fluid to accurately estimate the TVS performance in normal gravity. The successful results for the ellipsoidal STUSTD modeling work further establishes a code validation database for two-phase, cryogenic tank analysis tools.

\section{Acknowledgments}

This work was supported by the NASA Marshall Space Flight Center under the Pressure Control Data Correlation contract NNM05AB18C.

\section{References}

${ }^{1}$ Grayson, G.D. and Lopez, A., "Cryogenic Tank Modeling for the Saturn AS-203 Experiment,” AIAA Paper 2006-5258, 09 March 2006.

2 Olsen, A.D., Cady, E.C., and Jenkins, D.S., "Solar Thermal Upper Stage Cryogen System Engineering Checkout Test," AIAA Paper 99-2604, June 1999.

${ }^{3}$ Lin, C.S., Van Dresar, N.T., and Hasan, M.M., “A Pressure Control Analysis of Cryogenic Storage Systems,” AIAA Paper 91-2405, June 1991.

${ }^{4}$ Winters, B.A., "Analysis of the Solar Thermal Upper Stage Technology Demonstrator liquid acquisition device with integrated thermodynamic vent system," AIAA Paper 96-2745, July 1996.

'FLOW-3D User's Manual, version 9.0, Flow Science, Inc., Santa Fe, NM 2005. 